\title{
Gallbladder Neoplasm
}

National Cancer Institute

\section{Source}

National Cancer Institute. Gallbladder Neoplasm. NCI Thesaurus. Code C3048.

A benign or malignant neoplasm affecting the gallbladder. Representative examples of benign neoplasms include lipoma, leiomyoma, and neurofibroma. Representative examples of malignant neoplasms include carcinoma, lymphoma, and sarcoma. 